\title{
Synchronous Primary Endometrium and Ovarian Carcinoma: A Case Report
}

\author{
Yasoda Rijal $^{1}$, Suraj Shrestha ${ }^{1}$, Laxmi Bogati ${ }^{2}$, Priyanka Regmi ${ }^{1}$, Sushi Shrestha ${ }^{1}$, Prabesh \\ Luintel $^{3}$, Chandra Yadav ${ }^{1}$, Bishal Khaniya ${ }^{1}$, and Suvana Maskey ${ }^{1}$ \\ ${ }^{1}$ Tribhuvan University Institute of Medicine \\ ${ }^{2}$ Manipal College of Medical Sciences \\ ${ }^{3}$ Kathmandu Medical College and Teaching Hospital
}

January 24, 2022

\begin{abstract}
Synchronous ovarian and endometrial tumor is a rare entity. We report a case of a 38-year woman with an endometrioid variant of synchronous primary endometrial and left ovarian carcinoma. Patient underwent total abdominal hysterectomy with bilateral salphingo-oophorectomy with lymphadenectomy and is disease free till 9 months.
\end{abstract}

\section{INTRODUCTION}

Synchronous tumors of the female genital tract are rare and make only about $1 \%$ of all genital malignancies. ${ }^{1-3}$ The most common synchronous tumor is synchronous endometrial and ovarian cancer and accounts for $50-70 \%$ of all. ${ }^{1}$ However, the majority of the cases are metastatic arising from one organ and simultaneous primary cancer involving both organs is uncommon. ${ }^{4}$

As the incidence of synchronous primary endometrial and ovarian carcinoma (SPEOC) is limited, it can easily be confused with endometrial cancer with ovarian metastasis. ${ }^{5}$ Thus, it is often challenging to diagnose such separate independent primary tumors and mandates careful consideration of a number of lesions, histological and immunohistochemical features as the two entities have different therapeutic and prognostic implications. ${ }^{6}$

We report a case of a 38-year woman with an endometrioid variant of synchronous primary endometrial and left ovarian carcinoma.

\section{CASE PRESENTATION}

A 46-year $\mathrm{P} 3_{+1} \mathrm{~L}_{3}$ regularly menstruating presented with a complaint of excessive per vaginal bleeding during the menstrual cycle for the past one and a half years. She used 4-5 pads/day, fully soaked with the passage of clots without dysmenorrhea. There was no history of intermenstrual bleed, post-coital bleed, and dyspareunia. Also, there was no other illness and no history of malignancy in the family.

On examination, she had a BMI of $25.2 \mathrm{~kg} / \mathrm{m}^{2}$ and her vitals were normal. Per abdominal examination was unremarkable. Per speculum examination revealed a healthy cervix with a bloodstain. On per vaginal examination, there was a left adnexal mass around $6 \mathrm{~cm} \mathrm{x} 5 \mathrm{~cm}$, firm to solid cystic, smooth, mobile, and non-tender with the groove felt between the mass and uterus. With the suspicion of an ovarian mass, routine investigations along with tumor markers were sent. (Table 1)

Table 1: Routine investigation and Tumor markers 
Transvaginal ultrasound showed a complex solid cystic lesion measuring $6.9 \mathrm{~cm} \times 5.3 \mathrm{~cm}$ with the fatty component within the left adnexa and a $3.3 \mathrm{~cm} \times 2 \mathrm{~cm}$ heteroechoic well-defined lesion arising from the posterior wall of the body of uterus likely fibroid with normal endometrial thickness. CT scan of the abdomen and pelvis revealed approximately $7.1 \mathrm{~cm} \mathrm{x} 4.8 \mathrm{~cm} \mathrm{x} 4.5 \mathrm{~cm}$ well defined heterogeneous solid cystic lesion in the left adnexa. The solid components showed heterogeneous enhancement in post-contrast images. Medially the mass was abutting the urinary bladder wall, laterally it was abutting the common iliac vessel and superiorly the bowel loops. The uterus was bulky measuring approx $9.6 \mathrm{~cm} \times 5.2 \mathrm{~cm}$ with mild heterogeneous collection noted in the endometrial cavity. (Figure 1) All the features were suggestive of left ovarian neoplasm. Endometrial biopsy was also done which showed atypical endometrial hyperplasia.

After the positive frozen section pathological examination in the ovaries, the patient underwent total abdominal hysterectomy with bilateral salphingo-oophorectomy with bilateral pelvic and para-aortic lymphadenectomy, omentectomy, appendectomy, and peritoneal biopsies. (Figure 2) Intraoperatively, there was an irregular mass of around $6 \mathrm{~cm} \times 6 \mathrm{~cm}$ arising from the left ovary. Cross-section of ovary revealed fatty material and cheesy material inside. There was no internal septation or papillary projection. The uterus was $10 \mathrm{~cm}$ with body and cervix $7 \mathrm{~cm}$ and $3 \mathrm{~cm}$ respectively with a rough towel appearance. Myometrial thickness was $3 \mathrm{~cm}$ with endometrial hyperplasia noted. The endocervical canal was empty. (Figure 3) Her post-operative period was unremarkable and was discharged on the $4^{\text {th }}$ postoperative day.

Histopathology of the excised specimens revealed endometrioid endometrial carcinoma and left ovarian endometroid carcinoma with histological grade 2. The tumor was limited to the inner half of the myometrium and $5 \mathrm{~mm}$ within the capsule of the ovary. Lymphovascular invasion was not seen. (Figure 4 and 5) Peritoneal cytological washing and biopsies, as well as lymph nodes, were negative for malignant cells. The final diagnosis of synchronous FIGO Ia endometroid endometrial carcinoma and FIGO Ia endometroid ovarian carcinoma was made. The patient is disease-free at nine months of follow-up with no evidence of recurrence.

\section{DISCUSSION}

SPEOC is found in approximately $10 \%$ of all females with ovarian cancer and in $5 \%$ of all females with endometrial cancer. As the entity is uncommon, it is often misdiagnosed as FIGO stage III of endometrial cancer or FIGO stage II of ovarian cancer. ${ }^{5}$ The majority of women with SEOC are 41-54 years old, $40 \%$ of them are nulliparous, $2 / 3$ of them are premenopausal, and $1 / 3$ are obese. ${ }^{7}$ In the reported case, the patient is multiparous, premenopausal, and had a BMI of $25.4 \mathrm{~kg} / \mathrm{m}^{2}$. Moreover, SPEOC is observed among the younger age group as compared to endometrial or ovarian cancer alone. ${ }^{8}$

As with this case, abnormal uterine bleeding is the most common presentation of synchronous endometrial and ovarian cancer, though some patients may present with pelvic pain or a palpable pelvic mass. ${ }^{7}$ In ultrasonography, most of the ovarian masses in SPEOC appear as unilateral multilocular-solid or solid mass but such ovarian masses in cases of endometrial cancers with ovarian metastasis are often solid masses bilaterally. ${ }^{9}$ Our patient also had a solid-cystic lesion in her left ovary only supporting this statement.

The Endometroid subtype of the primary tumors is the commonest histological finding which is found in $50-70 \%$ of cases and the primary independent tumors often grade 1 or $2 .{ }^{7}$ In the reported case, it was endometroid subtype with histological grade 2.Development of surface epithelium of the ovary from the embryological Mullerian duct and sharing of estrogen receptors in predisposed tissues are the likely reasons for their synchronous growth. ${ }^{10}$ Because of this common histological finding in both the localization, differentiation of the primary origins from primary endometrial cancer with metastases to ovaries, or primary ovarian cancer with metastases to the endometrium is pivotal. ${ }^{11}$ In our case, histology revealed no evidence of metastasis as the tumor from the section of endometrium was limited to the inner half of the myometrium and $5 \mathrm{~mm}$ within the capsule of the ovary without lymphovascular invasion. 
Although primary surgery has been recognized as the main treatment for SPEOC, whether adjuvant therapy should be administered remains controversial. Using FIGO guidelines, a patient with dual primaries limited to the ovary and the uterus represents two Stage I cancers. Systematic surgical staging is the mainstay of the management for such patients and often includes total abdominal hysterectomy with bilateral salpingooophorectomy, total omentectomy, appendectomy, pelvic and para-aortic lymphadenectomy, and complete resection of all diseases. ${ }^{10}$ Considering the positive frozen section examination, our patient too underwent the aforementioned staging surgery.

These patients have a good prognosis and depending on the substage may not require radio or chemotherapy. However, no guidelines for adjuvant therapy in patients with synchronous cancers have been established yet and the treatment of respective cancer guides the adjuvant treatment. In ovarian cancer, all but stage IA/B are to receive chemotherapy and in endometrial cancer, it is indicated when the risk of distant metastasis is high. ${ }^{11}$ Considering stage Ia of the ovarian tumor, adjuvant chemotherapy was not given to our patient.

The prognosis of patients with synchronous endometrial and ovarian carcinoma is better than the patients with single-organ cancer with ovarian or endometrial spread with the median 5-year disease-free survival (DFS) rate reported to be $65 \%$ for synchronous endometrial and ovarian cancer but is less than $50 \%$ for stage IIIA endometrial cancer with ovarian spread. ${ }^{12},{ }^{13} \mathrm{~A}$ review of 43 cases of SPEOC showed that nine patients had recurrence (20.93\%). The median time to recurrence was 10 months (range, 5-30). The five-year survival rate of the patients was $86.05 \% .^{8}$ In addition, A study of double cancer in 1500 patients showed that the prognosis improved with younger age (less than 55 years), earlier stage, lower stage, the premenopausal state, and lymph node dissection. ${ }^{13}$ Also, synchronous primary endometrial and ovarian cancer endometroid types have better overall survival than patients with non-endometrioid or mixed histologic types. ${ }^{14}$ Considering all, the prognosis of our patient is good and our patient is now disease-free at nine months of surgery and is under regular follow-up.

\section{CONCLUSION}

Synchronous endometrial and ovarian tumors are rare variants of gynecological cancers. However, young women with endometrial cancer can have synchronous ovarian cancer. They must be differentiated from either primary endometrium or ovarian tumors with metastasis.

\section{Abbreviations}

SPEOC: Synchronous primary endometrial and ovarian carcinoma

SEOC: Synchronous endometrial and ovarian carcinoma

DFS: Disease free survival

FIGO: The International Federation of Gynaecology and Obstetrics

Ethics approval and consent to participate: Not required

Consent for publication : Written informed consent was obtained from the patient and her husband for publication of this case report and accompanying images. A copy of the written consent is available for review by the Editor-in-Chief of this journal on request.

Availability of data and materials : All the necessary data and materials are within the manuscript.

Competing interests : None to declare.

Funding : Not available.

Authors' contributions : Suvana Maskey(SM),Bishal Khaniya(BK), Chandra Narayan Yadav(CNY)= Study concept, Data collection, and surgical therapy for the patient

Yasoda Rijal (YR),Suraj Shrestha(SS), Chandra Narayan Yadav(CNY) = Writing- original draft preparation

Laxmi Bogati(LB), Priyanka Regmi(PR), Sushi Shrestha(SS), Prabesh Luitel(PL) = Editing and writing 
$\mathrm{SM}$ and $\mathrm{BK}=$ senior author and manuscript reviewer

All the authors read and approved the manuscript.

Acknowledgments : None

Authors' information (optional)

1. Yasoda Rijal, Maharajgunj Medical Campus, Institute of Medicine, Kathmandu, Nepal. Email: rijalyasoda1221@gmail.com

2. Suraj Shrestha, Maharajgunj Medical Campus, Institute of Medicine, Kathmandu, Nepal. Email: multisurazz@gmail.com

3. Laxmi Bogati, Manipal College of Medical Sciences, Teaching Hospital. Email:drlaxmibogati@gmail.com

4. Priyanka Regmi, Maharajgunj Medical Campus, Institute of Medicine,Kathmandu Nepal.Email:priyanka.regmi7@gmail.com

5. Sushi Shrestha, Maharajgunj Medical Campus, Institute of Medicine, Kathmandu, Nepal. Email:sushishrestha01@gmail.com

6. Prabesh Luitel, Kathmandu Medical College, Kathmandu University Email:prluintel095@gmail.com

7. Chandra Narayan Yadav,Department of Obstetrics and Gynecology, Tribhuvan University Teaching Hospital, Kathmandu,Nepal.Email:cy87010@gmail.com

8.Bishal Khaniya,Department of Obstetrics and Gynecology, Tribhuvan University Teaching Hospital, Kathmandu,Nepal.Email:bishalkhaniya92@gmail.com

9. Suvana Maskey,Department of Obstetrics and Gynecology, Tribhuvan University Teaching Hospital, Kathmandu,Nepal.Email: maskeysuvna@gmail.com

\section{REFERENCES}

1. Patru CL, Marinas MC, Drocas I, et al. Synchronous Primary Ovarian and Endometrial Carcinomas in a Young PatientCase report and literature review. Rev Chim. 2020;70(12):4360-4365. doi:10.37358/rc.19.12.7758

2. Pasam MK, Rajendiran S, Susruthan M, Rani U. Synchronous Primary Ovarian Mucinous Carcinoma and Endometrioid Endometrial Carcinoma : A rare case report. Ann Pathol Lab Med. 2017;4(4):C119-C123. doi:10.21276/apalm.1295

3. Sandoval Martínez D, García Ayala E, Mayorga Anaya H. Neoplasia primaria sincrónica de endometrio y ovario: a propósito de un caso. Rev Chil Obstet Ginecol. 2011;76(2):113-117. doi:10.4067/s071775262011000200008

4. Ree Y-S, Cho S-H, Kim S-R, Cho S-H, Kim K-T, Park M-H. Synchronous primary endometrial and ovarian cancer with three different histologic patterns: A case report.Int J Gynecol Cancer. 2003;13(5):678682. doi:10.1136/ijgc-00009577-200309000-00017

5. Wang T, Zhang X, Lu Z, Wang J, Hua K. Comparison and analysis of the clinicopathological features of SCEO and ECOM. J Ovarian Res. 2019;12(1):10. doi:10.1186/s13048-019-0485-5

6. Grammatoglou X, Skafida E, Glava C, Katsamagkou E, Delliou E, Vasilakaki T. Synchronous endometrioid carcinoma of the uterine corpus and ovary. A case report and review of the literature. Eur J Gynaecol Oncol. 2009;30(4):437-439. https://www.ncbi.nlm.nih.gov/pubmed/19761140

7. Makris G-M, Manousopoulou G, Battista M-J, Salloum I, Chrelias G, Chrelias C. Synchronous Endometrial and Ovarian Carcinoma: A Case Series. Case Rep Oncol. 2017;10(2):732-736. doi:10.1159/000479501 
8. Liu Y, Li J, Jin H, Lu Y, Lu X. Clinicopathological characteristics of patients with synchronous primary endometrial and ovarian cancers: A review of 43 cases. Oncol Lett. 2013;5(1):267-270. doi:10.3892/ol.2012.943

9. Moro F, Leombroni M, Pasciuto T, et al. Synchronous primary cancers of endometrium and ovary vs endometrial cancer with ovarian metastasis: an observational study. Ultrasound Obstet Gynecol. 2019;53(6):827835. doi:10.1002/uog. 20213

10. Khan M, Amin SV, Srinivas SB, Shivananda RP, Patil N. Hydrosalpinx as a Rare Presentation of Synchronous Ovarian and Endometrial Carcinoma - A Case Report. J Clin Diagn Res. 2016;10(7):QD01QD03. doi:10.7860/JCDR/2016/18304.8102

11. Dębska-Szmich S, Czernek U, Krakowska M, et al. Synchronous primary ovarian and endometrial cancers: a series of cases and a review of literature. Prz Menopauzalny. 2014;13(1):64-69. doi:10.5114/pm.2014.41084

12. Eswari V, Prakash G, Ansari IA, Bhanumathy V, Palvannanathan G. Endometrioid carcinoma of the ovary and uterus - Synchronous primaries or metastasis: A case report. J Clin Diagnostic Res . 2011;5(4).

13. Song T, Seong SJ, Bae D-S, et al. Prognostic factors in women with synchronous endometrial and ovarian cancers. Int J Gynecol Cancer. 2014;24(3):520-527. doi:10.1097/IGC.0000000000000073

14. Khalid N, Ullah F, Zafar H, et al. Synchronous Primary Endometrial and Ovarian Cancers: Trends and Outcomes of the Rare Disease at a South Asian Tertiary Care Cancer Center. Cureus. 2020;12(7):e9163. doi:10.7759/cureus.9163

\section{FIGURES WITH LEGENDS}




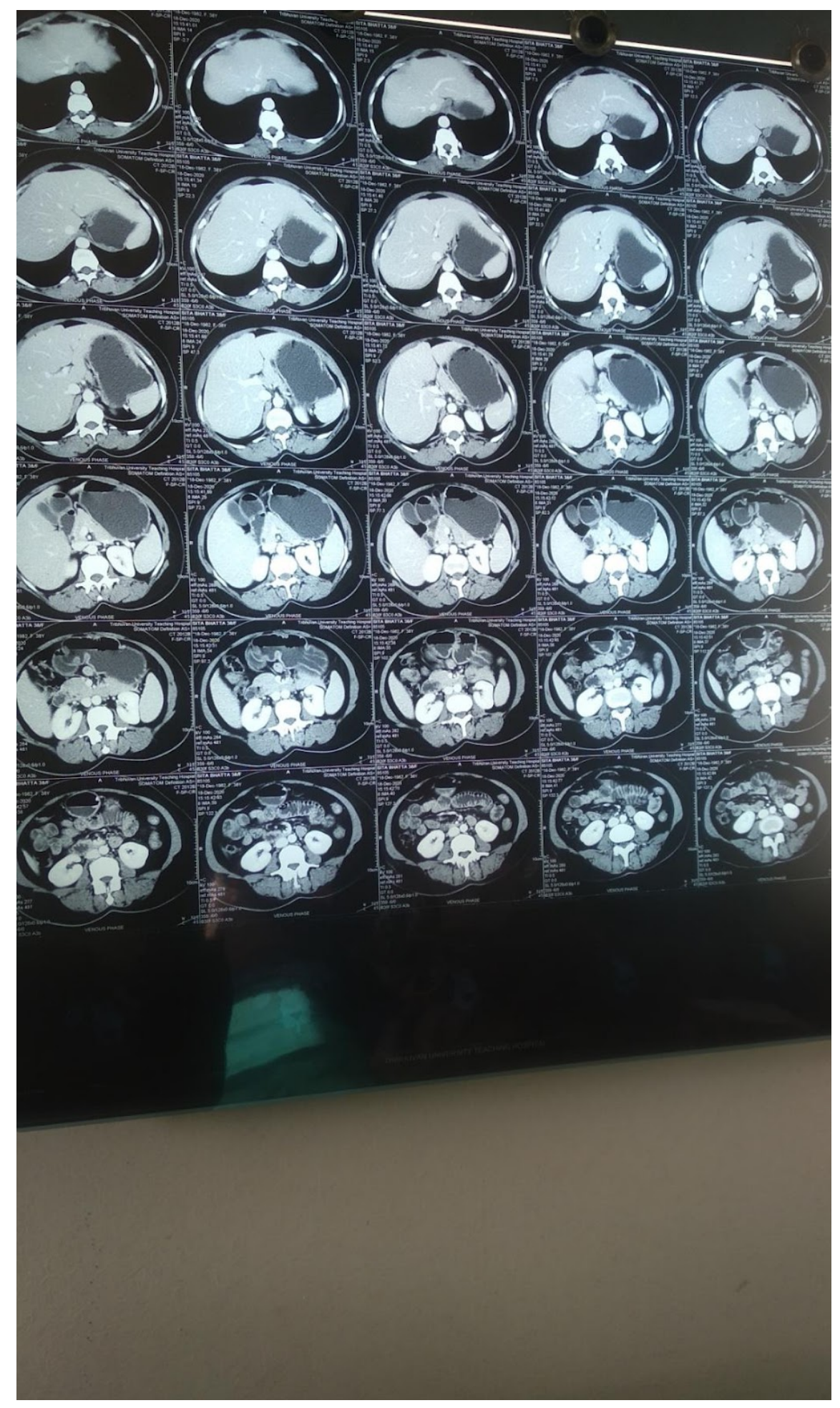

Figure 1: CT scan of abdomen and pelvis shows a well-defined heterogeneous solid cystic lesion in the left adnexa; features suggestive of ovarian neoplasm. 


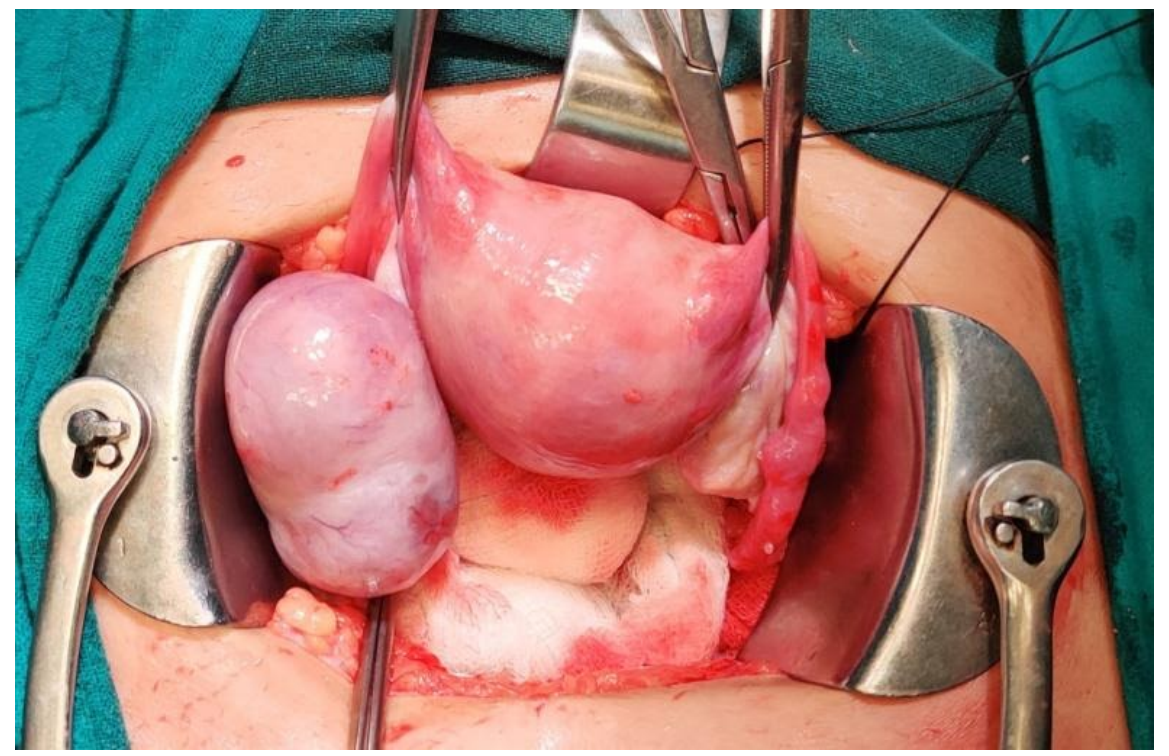

Figure 2: Intraoperative image showing bulky left ovary.

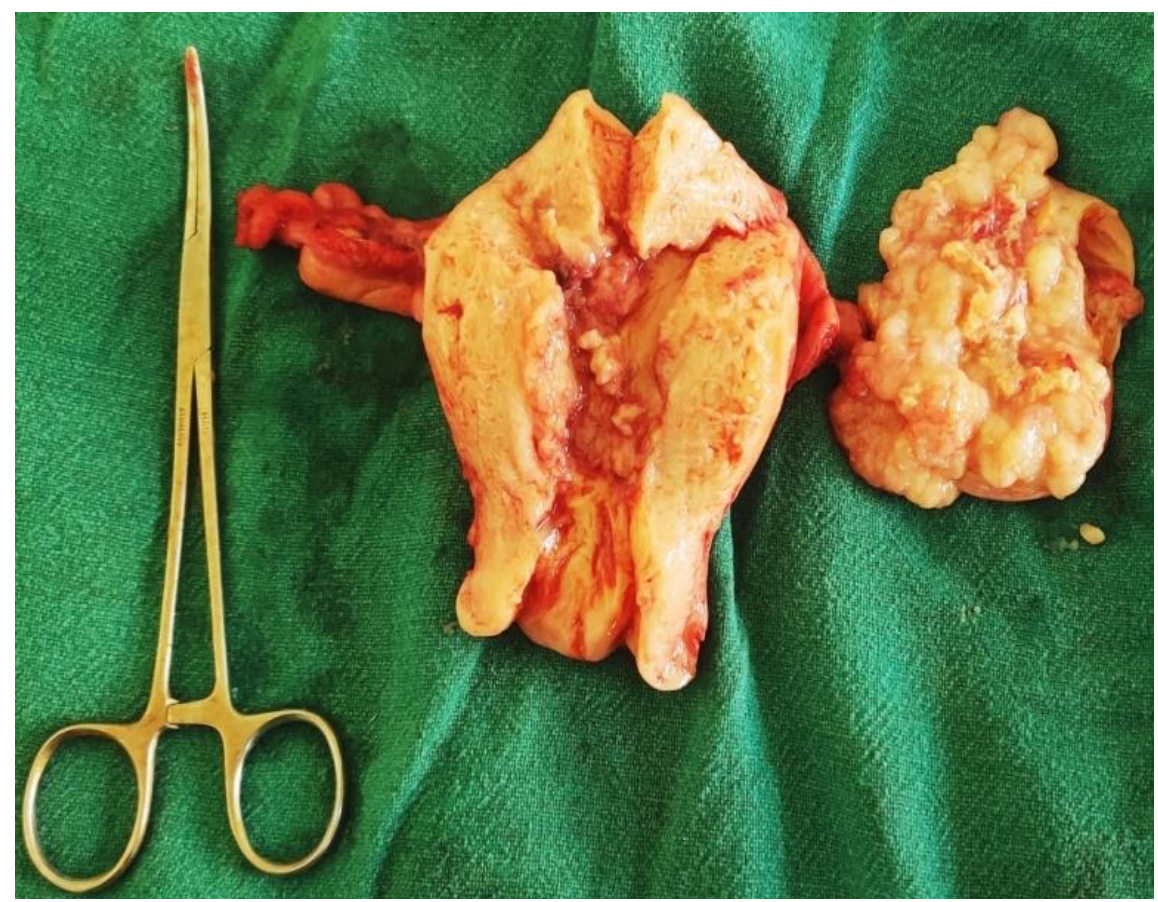

Figure 3: Specimen of the excised uterus and the left ovary which shows fatty/cheesy material with no projections or septations and an empty endocervical canal. 


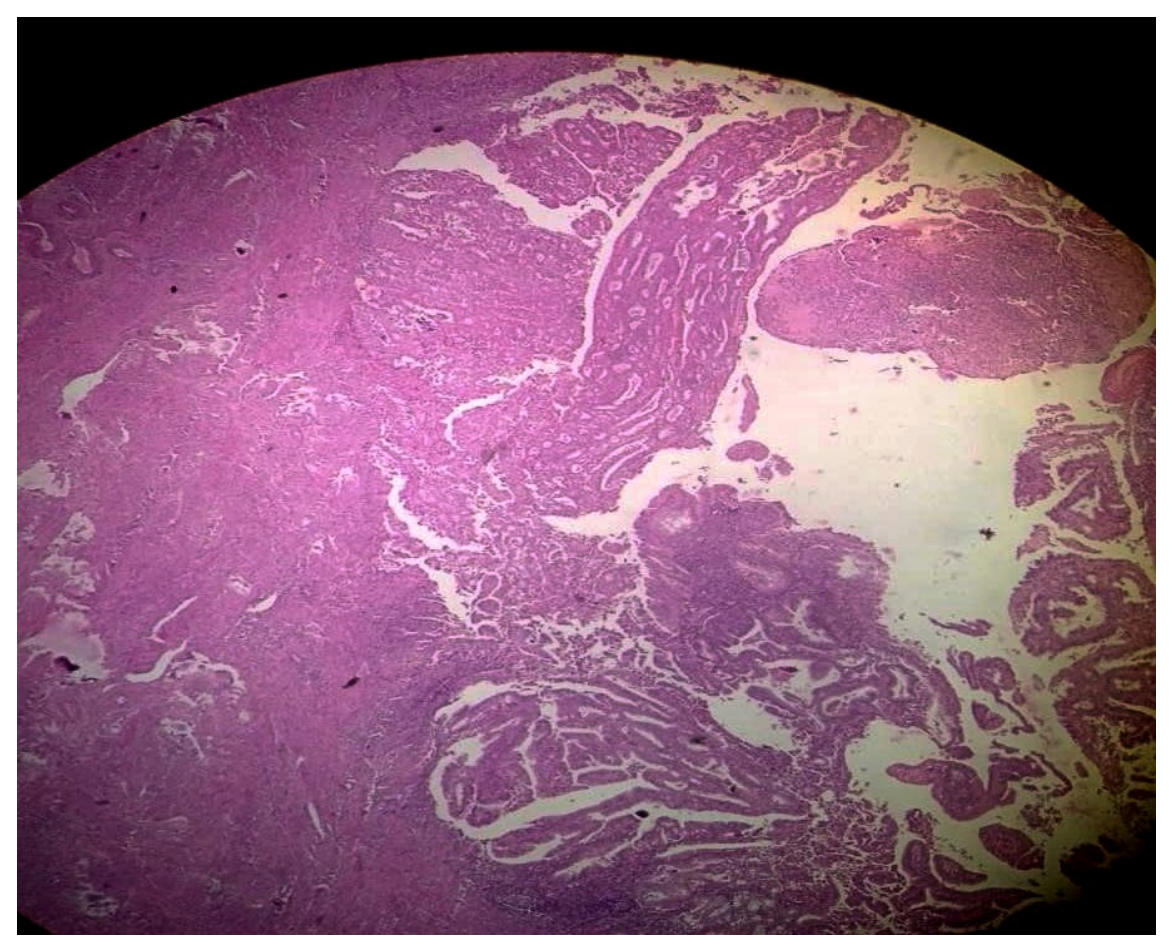

$\mathrm{r}$

Figure 4: Section from endometrium shows tumor cells lined by pseudostratified columnar epithelium showing mild nuclear polymorphism. Invasion into less than half of the myometrium is seen without lymphovascular and perineural invasion. 


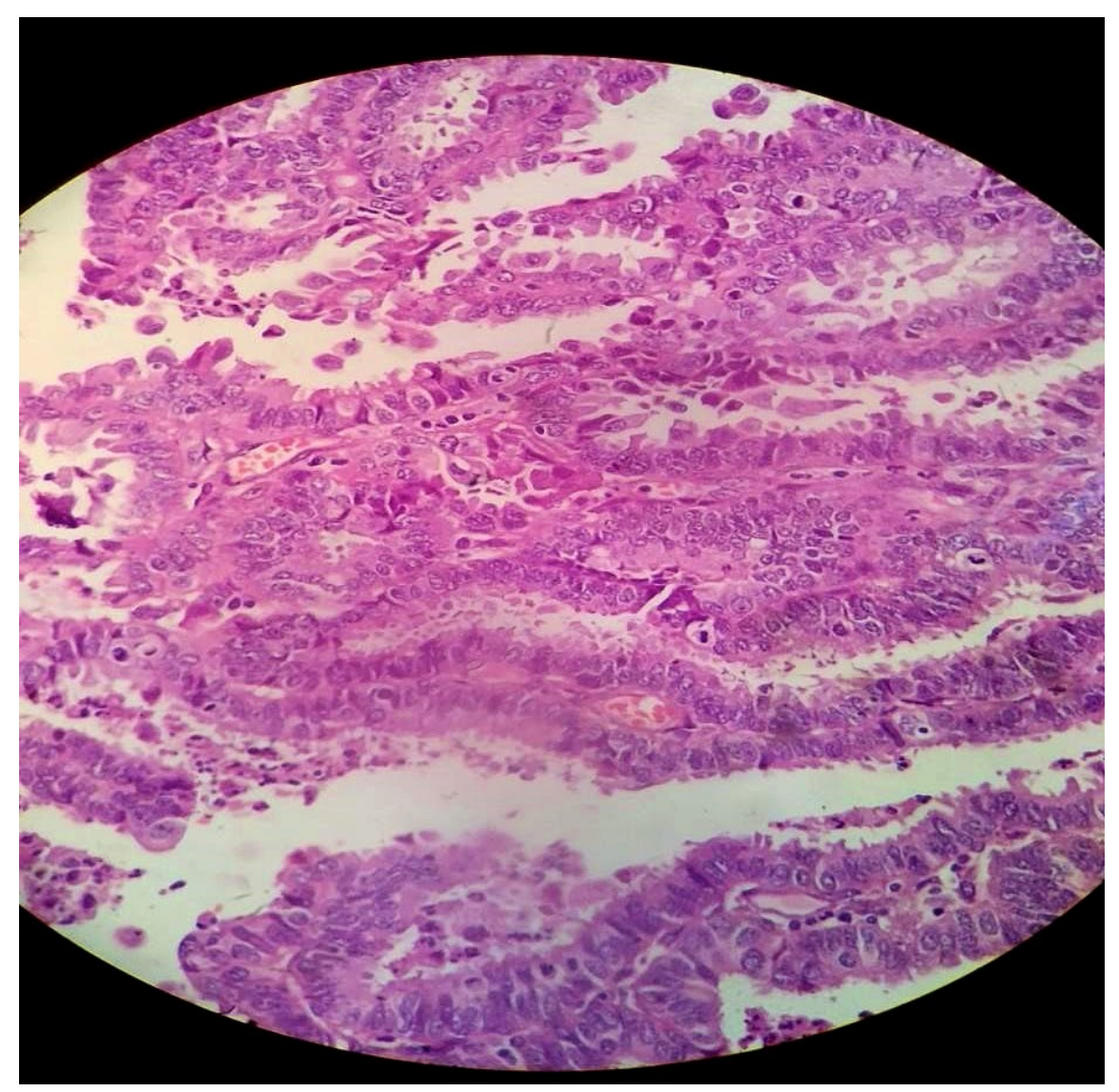

Figure 5: Section from left ovary shows tumor cells arranged in papillae, tubules and micro papillae showing moderate atypia.Tumor cells have moderate amount of eosinophilic to granular cytoplasm, vesicular nuclei and inconspicuous nucleoli .Tumor is $5 \mathrm{~mm}$ away from capsule; capsular invasion not seen. 

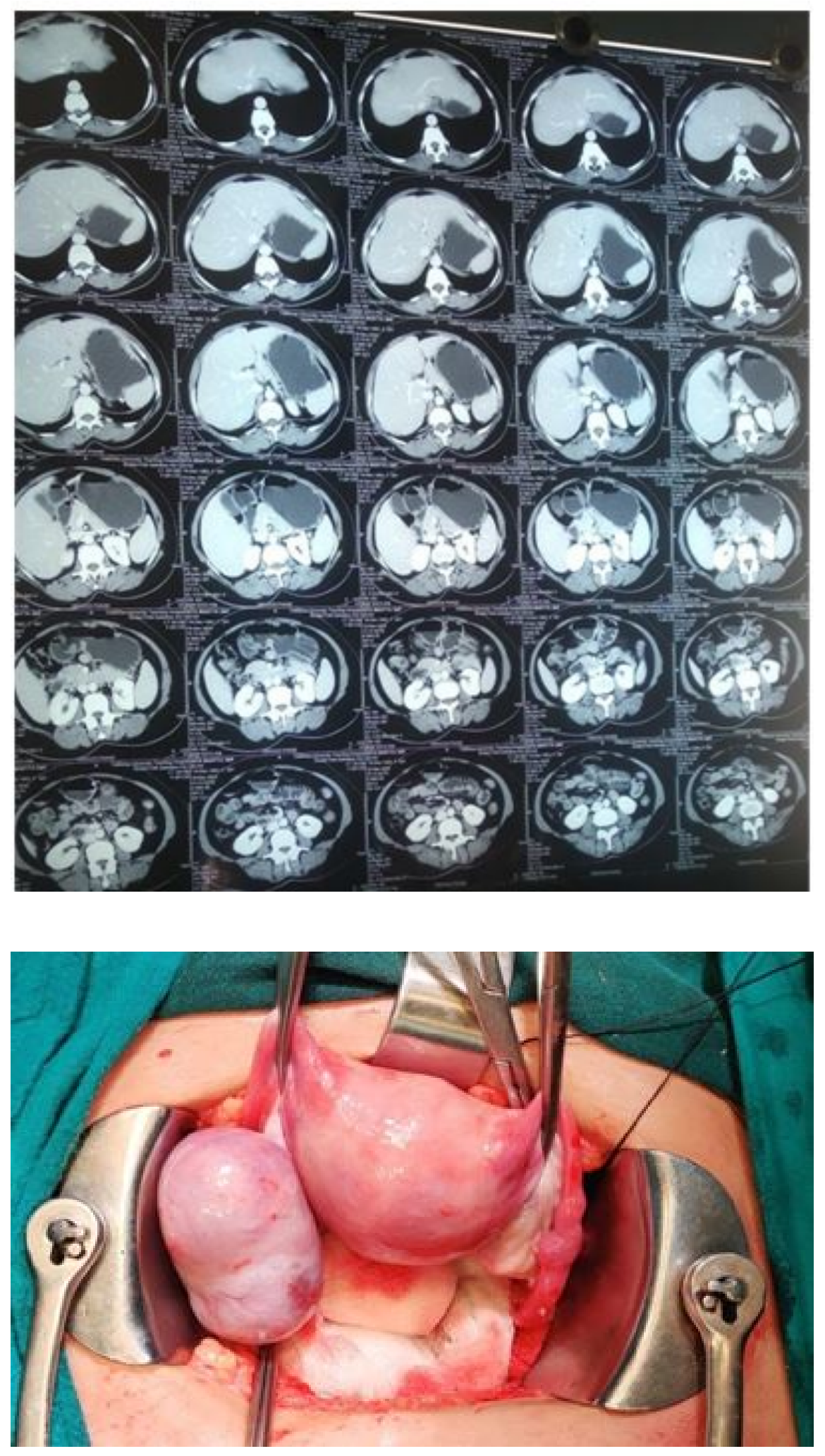

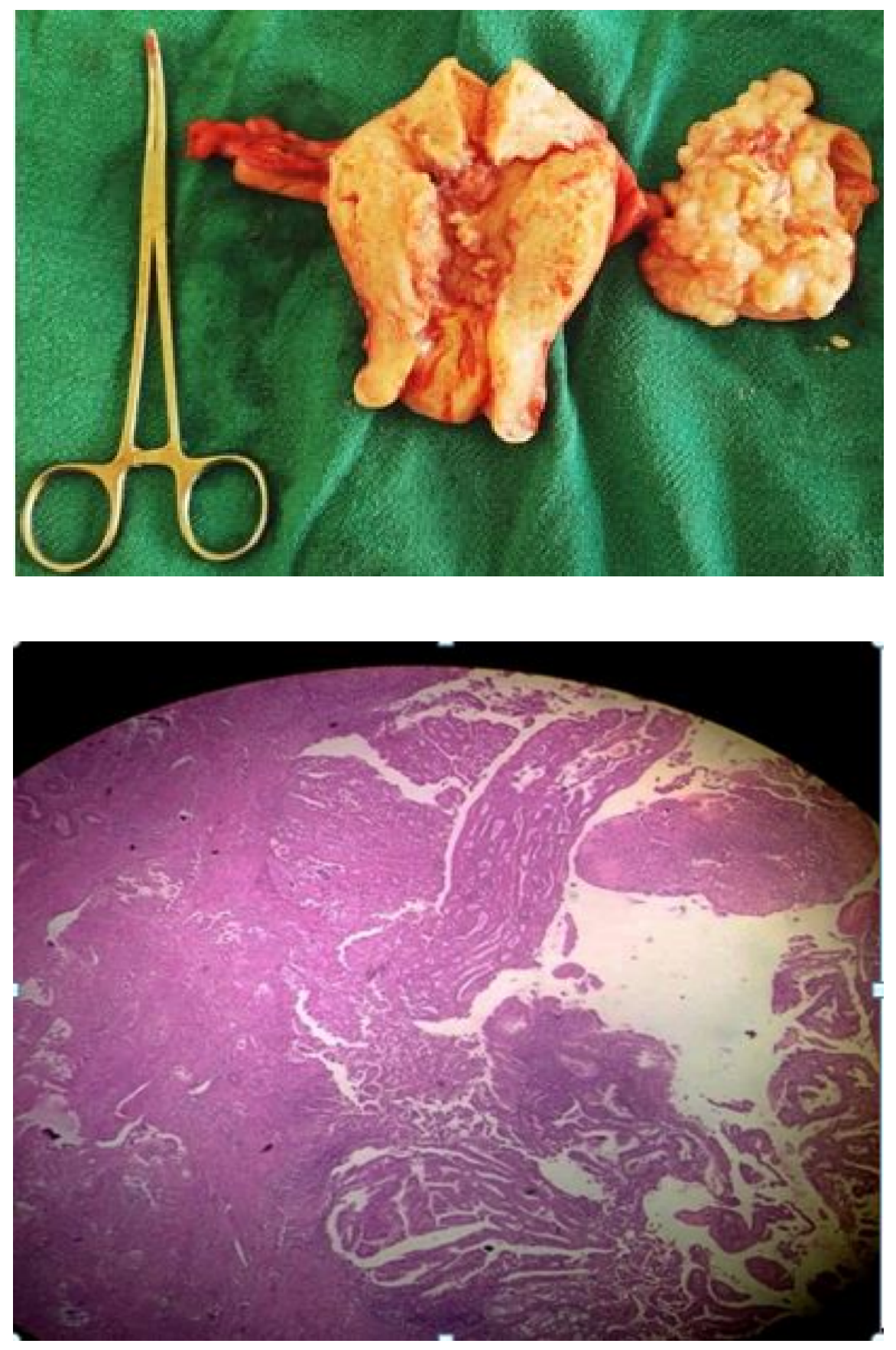


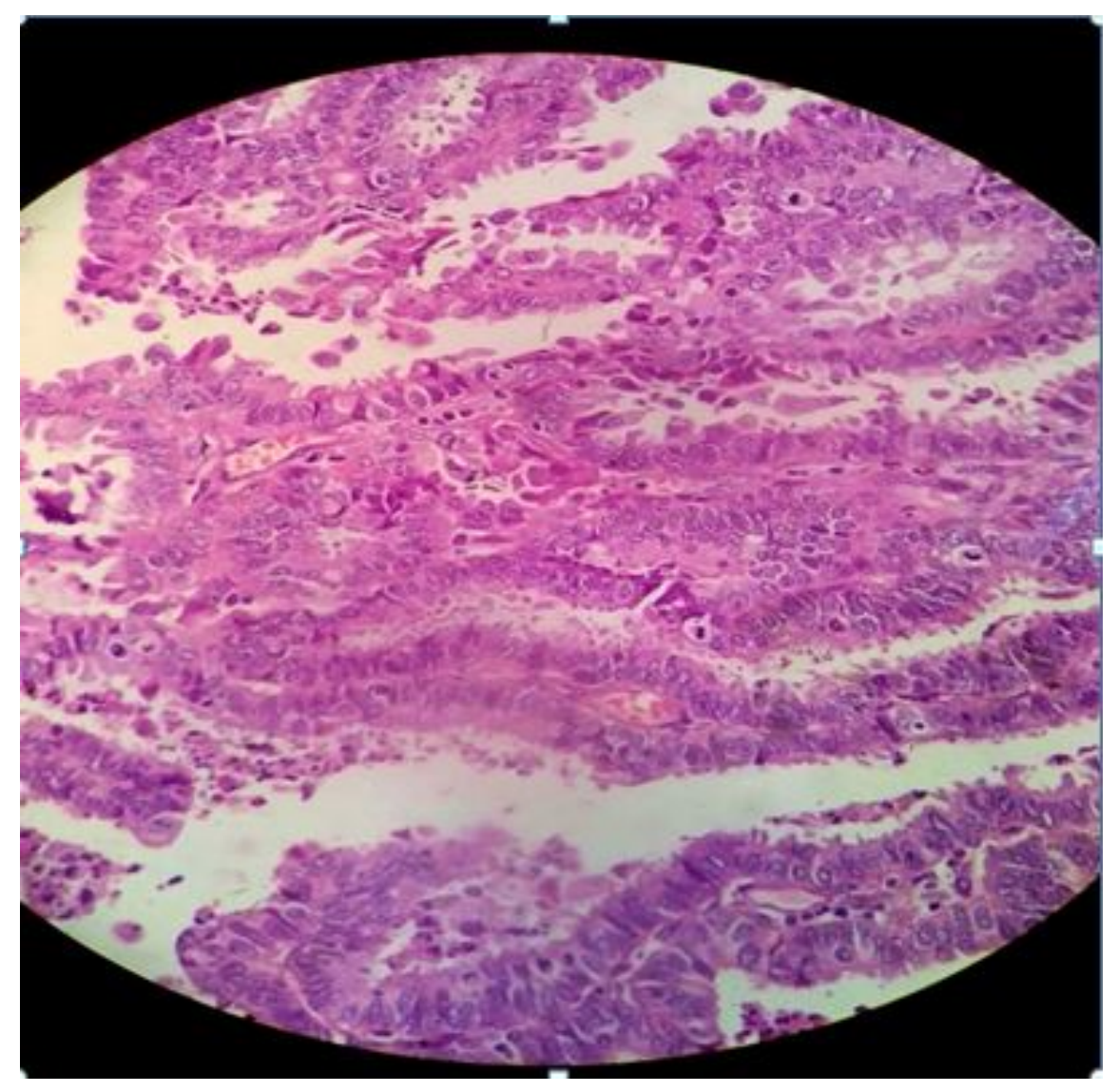

